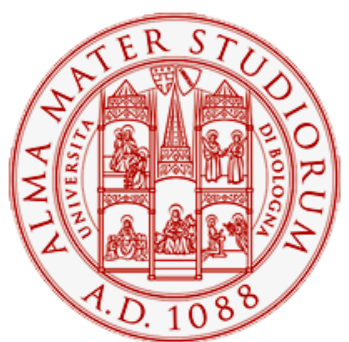

Alma Mater Studiorum - Università di Bologna DEPARTMENT OF ECONOMICS

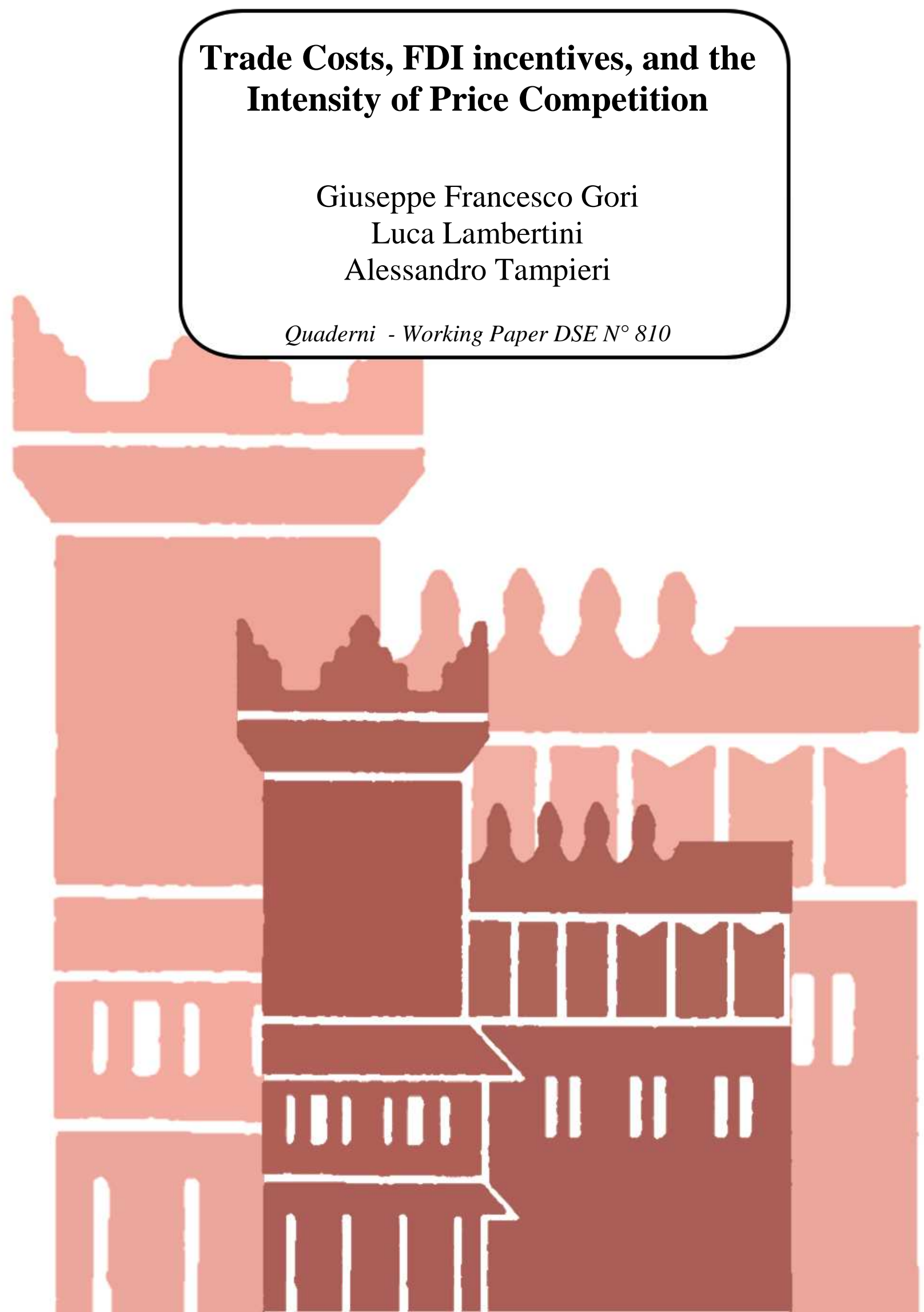




\title{
Trade Costs, FDI incentives, and the Intensity of Price Competition
}

\author{
Giuseppe Francesco Gori* $\quad$ Luca Lambertini ${ }^{\dagger}$ \\ Alessandro Tampieri ${ }^{\ddagger}$
}

February 9, 2012

\begin{abstract}
Empirical evidence shows that an increase in trade liberalisation causes an increase in foreign direct investments (FDIs). Here we propose an explanation to this apparent puzzle by exploiting the intensity of competition in a Bertrand duopoly with convex costs where the two firms enter in a new market. We adopt Dastidar's (1995) approach, delivering a continuum of Bertrand-Nash equilibria ranging above marginal cost pricing, to show that softening competition may indeed more than offset the standard effect generated by trade costs, thereby leading to a positive relationship between trade liberalisation and FDIs.
\end{abstract}

JEL Numbers: F12, F13, F23

Keywords: trade liberalisation, foreign direct investment, Bertrand duopoly

*Department of Economics, University of Bologna. Strada Maggiore 45, 40125 Bologna, Italy. Email: giuseppe.gori@unibo.it.

${ }^{\dagger}$ Department of Economics, University of Bologna. Strada Maggiore 45, 40125 Bologna, Italy. Email: luca.lambertini@unibo.it.

${ }_{\ddagger}^{\ddagger}$ Department of Economics, University of Bologna. Strada Maggiore 45, 40125 Bologna, Italy. Email: alessandro.tampieri@unibo.it. 


\section{Introduction}

The standard theory of multinational corporations suggests that a decrease in trade tariffs would reduce the amount of foreign direct investment (FDI). ${ }^{1}$ Indeed, the adoption of FDIs has the aim to avoid tariffs by installing productive capacity in the country of the market where the firm operates (the so-called tariff-jumping argument). Nonetheless, stylised facts on FDIs show that the increase in trade liberalisation has led in fact to an increase in the volume of FDIs. ${ }^{2}$ In a recent contribution, Collie (2011) explains this paradox in a setting with two regions and two countries in each of them, Cournot competition and linear costs. He shows that multilateral trade liberalisation may induce firms to shift from exporting to FDIs if the inter-regional transport cost is sufficiently high. ${ }^{3}$

We propose an alternative explanation in a setting where two Bertrand firms, supplying a homogeneous good with a convex cost function, enter the market of a foreign country. They choose between exporting, which involves a linear cost associated with either shipping or tariffs, or undertaking FDIs, involving a sunk cost. We model Bertrand competition as in Dastidar (1995), yielding a continuum of Nash equilibria, ranging also above marginal cost pricing. Our results show that the paradox of an increase in FDI as trade liberalisation increases can be explained on the basis of the intensity of price competition in the host market, provided the FDI sunk costs are sufficiently low for the FDI strategy to be viable.

\footnotetext{
${ }^{1}$ Some relevant contributions in this field are Horstmann and Markusen (1992), Motta (1992) and Rowthorn (1992), inter alia.

${ }^{2}$ See Maruksen (2002) and Barba Navaretti and Venables (2004).

${ }^{3}$ An alternative and solid explanation to this paradox can be found in the literature on tax competition and FDI, according to which trade libelisation can increase FDI if countries favour foreign investments through a low taxation. Some noteworthy contributions are Janeba (1995), Haufler and Wooton (1999, 2006), Raff (2004) and Davies et al. (2010), inter alia.
} 


\section{The model}

We consider a world with two countries, labelled 1 and 2 . In country 1 there are two firms, labelled A and B. They produce the same homogeneous good, and have symmetric and convex production costs:

$$
C=c q^{2}
$$

where $q$ is the quantity produced by each firm and $c>0$. Consider a scenario in which both firms can supply the market of country 2, hosting no home firms at all. Let the inverse demand expressed by consumers of country 2 be linear:

$$
p=1-2 q \text {. }
$$

Firms A and B can enter country 2 in two alternative ways, namely, by (i) exporting from country 1 or (ii) undertaking FDIs. In the first case, they bear a cost $t \in(0,1)$ for each unit exported, which can be interpreted either as a transportation cost or a tariff, and thus obtaining profits:

$$
\pi_{e x}=p q-c q^{2}-t q
$$

while in the alternative case they incur the sunk costs $k>0$, with profits:

$$
\pi_{F D I}=p q-c q^{2}-k
$$

\section{Results}

According to Dastidar (1995), if firms have symmetric convex costs and compete à la Bertrand, the Nash equilibrium is necessarily non-unique. In particular, a pure-strategy Nash equilibrium is characterised by both firms setting the same price $p^{*}$, which is bounded by two thresholds $p^{a v c} \leq p^{*} \leq p^{u}$. The lower bound $p^{a v c}$ (the superscript avc stands for average variable cost) equals 
average variable costs, letting firms be indifferent between either producing at $p^{*}$ or producing nothing at all. The upper bound $p^{u}$ (with superscript $u$ standing for undercutting) is the price at which firms are indifferent between choosing price $p^{u}$, and marginally undercutting it in order to capture the entire demand at $p^{u}$.

If both firms export their respective home plants, the level of $p^{a v c}$ is given by equating the inverse demand function to the average variable cost (which includes the trading cost):

$$
1-2 q=c q+t,
$$

then solving for $q$ and substituting in the demand function we obtain:

$$
p_{e x}^{a v c}=\frac{c+2 t}{2+c} .
$$

The upper bound of the equilibrium price obtains by imposing indifference between duopoly profits (3) and the monopoly profits generated by undercutting:

$$
p q-c q^{2}-t q=2 p q-4 c q^{2}-2 t q .
$$

Solving for $p$, we obtain

$$
p_{e x}^{u c}=\frac{3 c+2 t}{2+3 c} .
$$

Finally, by equating the inverse demand function to the marginal cost, solving for $q$ and substituting into $p$, we obtain the price equal to marginal cost:

$$
p_{e x}^{m c}=\frac{c+t}{1+c},
$$

where the superscript $m c$ stands for marginal cost pricing.

The continuum of Nash equilibria can be represented by the following 
expression: ${ }^{4}$

$$
p_{e x}^{*}=\frac{c+(2-\alpha) t}{2+c-\alpha} .
$$

Parameter $\alpha$ represents the relative intensity of price competition between firms. Note that, when $\alpha=0$, in equilibrium price equals average variable cost; $\alpha=1$ corresponds to the Bertrand reference case in which price is equal to marginal cost, while at $\alpha=4 / 3$ the price attains the highest level above which undercutting takes place. As a consequence, $\alpha \in[0,4 / 3]$. Using (10), the individual profit function (3) writes:

$$
\pi_{e x}^{*}=\frac{\alpha c(2-\alpha)(1-t)^{2}}{4(2+c-\alpha)^{2}} .
$$

The per-firm equilibrium profits obtained by undertaking FDI can be easily found by setting $t=0$ in equation (11) and subtracting the FDI sunk cost $k$ :

$$
\pi_{F D I}^{*}=\frac{\alpha c(2-\alpha)}{4(2+c-\alpha)^{2}}-k .
$$

Of course, in order for $\pi_{F D I}^{*}$ to be positive, the following condition must hold: ${ }^{5}$

$$
k<\widehat{k}=\frac{\alpha c(2-\alpha)}{4(2+c-\alpha)^{2}} .
$$

the straightforward implication of (13) is that exporting is the only viable strategy for all $k>\widehat{k}$. By comparing $\pi_{e x}^{*}$ with $\pi_{F D I}^{*}$, it emerges that $\pi_{F D I}^{*}-$ $\pi_{e x}^{*}>0$ for all

$$
k<\widetilde{k}=\frac{\alpha c(2-\alpha)(2-t) t}{4(2+c-\alpha)^{2}} .
$$

Finally, note that:

$$
\widehat{k}-\widetilde{k}=\frac{\alpha c(2-\alpha)(1-t)^{2}}{4(2+c-\alpha)^{2}}>0 .
$$

\footnotetext{
${ }^{4}$ For an analogous application of Dastidar's (1995) approach, see André et al. (2009).

${ }^{5}$ This must be imposed as we are not imposing the price to cover average total costs.
} 
This leads to the following proposition:

Proposition 1 For all $k \in[0, \tilde{k}]$, both firms undertake FDIs to install capacity in the host country. For all $k>\widetilde{k}$, both firms choose to export from their home sites.

We are now in a position to exploit this result in order to explain the puzzle for which trade liberalisation leads to an increase in the volume of FDIs. This can be ascertained by evaluating the relationship between $\widetilde{k}$, whose increase leads to an increase in FDI, and $t$, whose decrease leads to an increase in trade liberalisation.

Totally differentiating $\widetilde{k}$ yields:

$$
d \widetilde{k}=\frac{\alpha c(2-\alpha)(1-t)}{2(2+c-\alpha)^{2}} d t-\frac{c[\alpha(1+c)-2-c](2-t) t}{4(2+c-\alpha)^{3}} d \alpha
$$

Examining (16), one observes that the coefficient of $d t$ is unambiguously positive for all admissible values of parameters. This feature is fully in line with the established theoretical wisdom dating back to Horstmann and Markusen (1992), Motta (1992) and Rowthorn (1992). Conversely, the coefficient of $d \alpha$ is negative for all

$$
\alpha>\frac{2+c}{1+c} .
$$

Note that

$$
\frac{2+c}{1+c} \geq \frac{4}{3} \text { for all } c \geq 2
$$

so that for $c<2$, the sign of the coefficient of $d \alpha$ in (16) may change depending on the level of $\alpha$. The ongoing discussion can be summarised in

Proposition 2 A positive relationship between trade liberalisation and FDI arises in the parameter region identified by $c<2$ and $\alpha \in((2+c) /(1+c), 4 / 3)$.

That is, the standard effect associated with trade liberalisation (i.e., a positive relationship between trade costs and FDIs) can indeed be reversed if 
(i) marginal cost is sufficiently low and (ii) the intensity of price competition is also sufficiently low. The intuitive reason is that increasing $\alpha$ in combination with a low marginal cost expands the mark up and therefore makes it easier for firms to bear the sunk cost of a new plant abroad.

Finally, we briefly discuss the different implications on the social welfare of the host country in the two alternative situations. In the case of export, we will consider, alternatively, $t$ as (i) a transportation cost or (ii) a tariff. If $t$ is meant to be a transportation cost, the host country's social welfare trivially coincides with its own consumer surplus, i.e.:

$$
W_{e x}^{t c}=\frac{(2-\alpha)^{2}(1-t)^{2}}{2(2+c-\alpha)^{2}},
$$

where superscript tc stands for transportation cost. Obviously, any increase in transportation costs hinders consumer surplus. Instead, if $t$ is a tariff, then the tariff revenue contributes to the host country's social welfare, together with consumer surplus:

$$
W_{e x}^{t a}=\frac{(2-\alpha)(1-t)[2-\alpha+t(2(1+c)-\alpha)]}{2(2+c-\alpha)^{2}},
$$

where the superscript ta stands for tariff. Clearly, $W_{e x}^{t a}>W_{e x}^{t c}$. Moreover, as $t$ here becomes a policy instrument in the hands of the host country's government, is can be easily established that

$$
\frac{\partial W_{e x}^{t a}}{\partial t} \propto c-t[2(1+c)-\alpha]=0
$$

in

$$
t^{*}=\frac{c}{2(1+c)-\alpha}
$$

Finally, in the case of FDI, again the host country's social welfare is given 
by its consumer surplus (the same as (19), with $t=0)$ :

$$
W_{F D I}=\frac{(2-\alpha)^{2}}{2(2+c-\alpha)^{2}} \text {. }
$$

We now compare the three alternatives. First note that $W_{F D I}>W_{e x}^{t c}$ for all $t>0$, while $W_{F D I}<W_{e x}^{t a}$ for all:

$$
t<\frac{2 c}{2(1+c)-\alpha}
$$

leading to

Corollary 3 The host country's social welfare ranking is $W_{e x}^{t a}>W_{F D I}>$ $W_{e x}^{t c}$.

This amounts to saying that imports are preferred to FDIs if and only if $t$ can be controlled by the host country to generate revenues more than offsetting the negative effect on consumer surplus. 


\section{References}

[1] André, F.J., González, P. and Porteiro, N. (2009). Strategic quality competition and the Porter hypothesis. Journal of Environmental Economics and Management 57: 182-194.

[2] Barba Navaretti, G. and Venables, A. J. 2004. Multinational Firms in the World Economy. Princeton, NJ, Princeton University Press.

[3] Collie, D.R. 2011. Multilateral trade liberalisation, foreign direct investment and the volume of world trade. Economics Letters 113: 47-49.

[4] Dastidar, G. S. 1995. On the existence of pure strategy Bertrand equilibrium. EconomicTheory 5: 9-32.

[5] Davies, R.B., Egger, H. and Egger, P. 2010. Profit taxation and the mode of foreign market entry. Canadian Journal of Economics 43: 704-727

[6] Haufler, A. and Wooton, I. 1999. Country size and tax competition for foreign direct investment. Journal of Public Economics 71: 121-139.

[7] Haufler, A. and Wooton, I. 2006. Regional tax coordination and foreign direct investment. European Economic Review 50: 285-305.

[8] Horstmann, I. J., and Markusen, J. R., 1992. Endogenous market structures in international trade (natura facit saltum). Journal of International Economics 32: 109-129.

[9] Janeba, E. 1995. Corporate income tax competition, double taxation treaties, and foreign direct investment. Journal of Public Economics 56: $311-325$.

[10] Markusen, J.R., 2002. Multinational Firms and the Theory of International Trade. Cambridge, MA, MIT Press. 
[11] Motta, M. 1992. Multinational firms and the tariff-jumping argument. European Economic Review 36: 1557-1571.

[12] Raff. H. 2004. Preferential trade agreements and tax competition for foreign direct investment. Journal of Public Economics 88: 2745-2763.

[13] Rowthorn, R.E., 1992. Intra-industry trade and investment under oligopoly: the role of market size. Economic Journal 102: 402-414. 


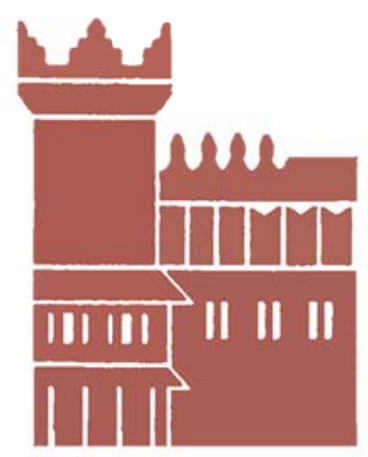

Alma Mater Studiorum - Università di Bologna DEPARTMENT OF ECONOMICS

Strada Maggiore 45

40125 Bologna - Italy

Tel. +39051 2092604

Fax +390512092664

http://www.dse.unibo.it 